\title{
Progesterone and ultrasonographic changes during aglepristone or cloprosternol treatment in queens at 21 to 22 or 35 to 38 days of pregnancy
}

\author{
M.C. García Mitacek ${ }^{a, b}$, M.C. Bonaura ${ }^{a, b}$, R.G. Praderio ${ }^{a, b}$, R. Nuñez Favre ${ }^{a, b}$, \\ R.L. de la Sota ${ }^{\text {a,b }}$, M.A. Stornelli ${ }^{\text {a,* }}$ \\ a Catedra y Servicio de Reproducción Animal, Facultad de Ciencias Veterinarias, Universidad Nacional de La Plata, La Plata, Argentina \\ ${ }^{\mathrm{b}}$ CONICET, CABA, Capital Federal, Argentina
}

\section{A R T I C L E I N F O}

\section{Article history:}

Received 2 May 2016

Received in revised form 27 September 2016

Accepted 28 September 2016

\section{Keywords:}

Queen

Pregnancy

Progesterone

Ultrasonography

Aglepristone

Cloprostenol

\begin{abstract}
A B S T R A C T
Progesterone $\left(\mathrm{P}_{4}\right)$ is a requirement for pregnancy development. Previous reports observed a maximal value of serum $\mathrm{P}_{4}$ concentration on 21 days after the first mating after which it slowly declines throughout the rest of pregnancy. Ultrasound examination should be performed to ensure that pregnancy interruption is complete. Limited information is available on the ultrasonic appearance of conceptuses during pregnancy termination in cats The objective was to study serum $\mathrm{P}_{4}$ concentration and ultrasonographic changes during aglepristone (ALI) or cloprostenol (CLO) treatment and to evaluate the fertility after treatment. Two experiments (EXP) were carried out to accomplish this aim. Sixty queens, 12- to 36-month-old, were used. On Days 21 to 22 of pregnancy (EXP I) or 35 to 38 of pregnancy (EXP II), queens were divided into three groups $(G)$. Queens in G1 received ALI ( $10 \mathrm{mg} / \mathrm{kg}, \mathrm{sc}$; EXP I, $n=10$; EXP II, $n=10)$ for 2 consecutive days. Queens in G2 received CLO ( $5 \mu \mathrm{g} / \mathrm{kg}$, sc; EXP I, $\mathrm{n}=10$; EXP $\mathrm{II}=10$ ) for 3 consecutive days. Queens in $\mathrm{G} 3$ received $1 \mathrm{~mL}$ of saline solution (PLA, sc; EXP I, $\mathrm{n}=10$; EXP II = 10). Blood samples were taken before treatment (Day 0 ) and every day during 10 days after the treatment to measure serum $\mathrm{P}_{4}$ concentrations. Likewise, after treatment, queens were monitored daily by ultrasonography for 10 days and weekly until the end of gestation to obtain gestational sacs measurements (GS), fetal measurements, and fetal biophysical profile. Data were analyzed by ANOVA. Serum $\mathrm{P}_{4}$ concentrations were significantly different on Day 6 (EXP I) and on Day 1 (EXP II) in ALI and CLO groups compared with PLA group ( $\mathrm{P}<0.05$ and $\mathrm{P}<0.01$; respectively). The ultrasonographic monitoring during treatment allowed assessing changes in the GS and fetal measurements, embryo-fetal viability, and risk of pregnancy loss. In conclusion, the results from this study reported changes in serum $\mathrm{P}_{4}$ concentration and in ultrasonography measurements during pregnancy interruption with ALI or CLO treatment. Also it was observed that ALI and CLO are safe drugs and can preserve posttreatment queen fertility. Therefore, the results obtained in our work will be applied in feline reproduction practice.
\end{abstract}

(c) 2016 Elsevier Inc. All rights reserved.

\footnotetext{
García Mitacek MC helped to design and conduct the experiment, process the samples, analyzed the data, and drafted the paper. Bonaura MC Praderio RG, and Nuñez Favre R helped to conduct the experiment and process the samples. De la Sota RL and Stornelli MA helped to design and conduct the experiment and critically revised the paper.

* Corresponding author. Tel.: +54423 66634455; fax: +542214257980.

E-mail address: astornel@fcv.unlp.edu.ar (M.A. Stornelli).
}

\section{Introduction}

Unobserved mating and unwanted pregnancy is common in sexually mature queens with outdoor access. In queens, pregnancy is usually detected on routine clinical examination during early or middle gestation. Several methods for pregnancies termination in queens have been 
described and reviewed in small animal reproduction. It has been reported that luteal function is dependent on prolactin support in middle and late gestation (between Days 34 and 42 of pregnancy; [1]). In addition, feline placenta is a source of progesterone $\left(\mathrm{P}_{4}\right)$ and can maintain pregnancy after Day 45 of gestation [2]. Thus, dopaminergic agents such as cabergoline have been used for induction of abortion after Day 30 of pregnancy to reduce serum prolactin concentrations but failed when started at Day 45 $[1,3]$. Combined treatment with prostaglandin analogues such as cloprostenol (CLO) or alfaprostol and cabergoline was more successful and side effects were significantly reduced $[1,4]$. Prostaglandin F2 $\alpha$ administration at Day 33 of pregnancy induces luteolysis and pregnancy termination with expulsion of fetuses [5]. Another alternative to induce abortion is the use of antiprogestins, such as aglepristone (ALI). Treatment with ALI has been proven to be safe and effective for early, middle, and late pregnancy termination in the queen [6-11].

Progesterone is a requirement for pregnancy development [12]. García Mitacek et al., [13] observed a maximal value of serum $\mathrm{P}_{4}$ concentration on 21 days after the first mating after which it slowly declines throughout the rest of pregnancy. These findings are in agreement with Zschockelt et al. [14], who found that intraluteal $\mathrm{P}_{4}$ concentrations were higher during development/maintenance (Day 14-36) compared to the regression luteal stages during the pregnancy (Day 38-63). In addition, identical intraluteal expression profiles of steroidogenic enzymes, as well as intraluteal contents of steroids, suggest that an on-going loss of steroidogenic capacity similarly causes a functional demise of the CL [14].

Ultrasonography is a noninvasive technique that permits an accurate diagnosis of pregnancy and allows serial evaluation of the developing embryo/fetus and extrafetal structures [15]. In addition, an ultrasound examination should be performed to ensure that pregnancy interruption is complete. Although several researchers have done many ultrasonography studies on queen pregnancy, limited information is available on the ultrasonic appearance of conceptuses during pregnancy termination in cats.

Fetal biophysical profile (FBP) scoring is used to predict the presence or absence of fetal hypoxia [16]. The FBP was developed by Manning et al. [17] in 1980 to evaluate the gestation in the woman. The original method of fetal biophysical profile scoring was based on a composite assessment of five variables: fetal breathing, gross body movements, tone, heart rate acceleration with fetal movement and amniotic fluid volume evaluated by real-time ultrasonography [16]. The FBP is noninvasive and easily applied, can be objectively evaluated, uses universally available equipment, and is highly accurate for predicting the presence of significant fetal hypoxemia or acidemia, which is indicative of fetal morbidity. A normal score predicts no fetal compromise and allows for conservative management in a gestation with high-risk factors, such as diabetes mellitus or hypertension. In contrast, an abnormal score in a similarly high-risk patient allows for weighing of relative fetal-neonatal risks and selection of delivery at a time when the balance shifts to greater fetal risk [16,17]. To our knowledge, the use of FBP during the pregnancy in queens has not been studied. Thus, the study of FBP in queens to predict the presence or absence of fetal compromise could be potentially useful in practice because it could provide important information for fetal surveillance in high-risk gestations in queens. In the same way, clinical management based on the FBP score could reduce perinatal mortality.

The aim of the study was to study serum $\mathrm{P}_{4}$ concentration and ultrasonographic changes during treatment with ALI or CLO and evaluate posttreatment fertility. Two experiments (EXP) were carried out to accomplish this objective. The hypothesis was that serum $\mathrm{P}_{4}$ concentration and conceptus ultrasonographic changes could be detected during the treatment with ALI or CLO and that both treatments would not interfere with subsequent fertility.

\section{Materials and methods}

Mixed breed queens ( $\mathrm{n}=60)$, age between 12 and 36 months and weighting between 2 and $4 \mathrm{~kg}$, were used in a randomized design [18]. In addition, two 3-year-old intact tomcats were used for breeding. The queens were housed in individual stainless steel cages and were fed commercial cat food (Fit 32; Royal Canin, Buenos Aires, Argentina) and water ad libitum. A physical examination of all animals included in the study was performed once a week. The toms were housed separately from queens and fed the same diet. All animals were maintained in a controlled environment with artificial incandescent illumination (14 hours of daily bright light; [19]). Animal care, housing, and experimentation complied with International Guiding Principles for Biomedical Research Involving Animals [20] and the approval of the IACUC of FCV UNLP (26-3-12). Queens were observed on a daily basis to detect estrous behavior, and receptivity to the male and vaginal cytology was performed to detect cytological estrus. When queens reported behavioral and cytological estrus, each queen was placed with the tom for 48 hours. The first mating was documented, and pregnancies were confirmed by abdominal palpation and transabdominal ultrasonographic examination using an ultrasound scanner equipped with a 5- to 7.5- to $10-\mathrm{MHz}$ linear transducer (MindrayTM, DP-6600 Vet, Nashan, China) 20 days after the first mating [15].

On Days 21 to 22 of pregnancy (EXP I) or 35 to 38 of pregnancy (EXP II), queens were divided into three groups (G). In G1, animals received 10-mg/kg ALI sc (Alizin, Virbac, Germany, ALI; EXP I, $\mathrm{n}=10$; EXP II, $\mathrm{n}=10$ ) on 2 consecutive days. In G2, animals received $5-\mu \mathrm{g} / \mathrm{kg}$ CLO sc (Ciclar p.a. , Zoovet, Argentina, CLO; EXP I, $\mathrm{n}=10$; EXP II, $\mathrm{n}=10$ ) on 3 consecutive days. In $\mathrm{G} 3$, animals received $1 \mathrm{~mL}$ of saline solution Sc (PLA; EXP I, $\mathrm{n}=10$; EXP II, $\mathrm{n}=10$ ). Blood samples were taken before administration the treatment (Day 0), during the treatment, and every day thereafter until Day 10 to measure serum $\mathrm{P}_{4}$ concentrations. All blood samples were centrifuged and stored at $-20{ }^{\circ} \mathrm{C}$ until $\mathrm{P}_{4}$ was measured by solid RIA using ${ }^{125}$ (Coat-A-Count, progesterone; Diagnostic Product Corporation, Los Angeles, CA, USA). The intraassay CVs for high-pool $(6.8 \mathrm{ng} / \mathrm{mL})$ and low-pool $\mathrm{P}_{4}(0.9 \mathrm{ng} / \mathrm{mL})$ were 3.9 , and $5.4 \%$, respectively. 
A

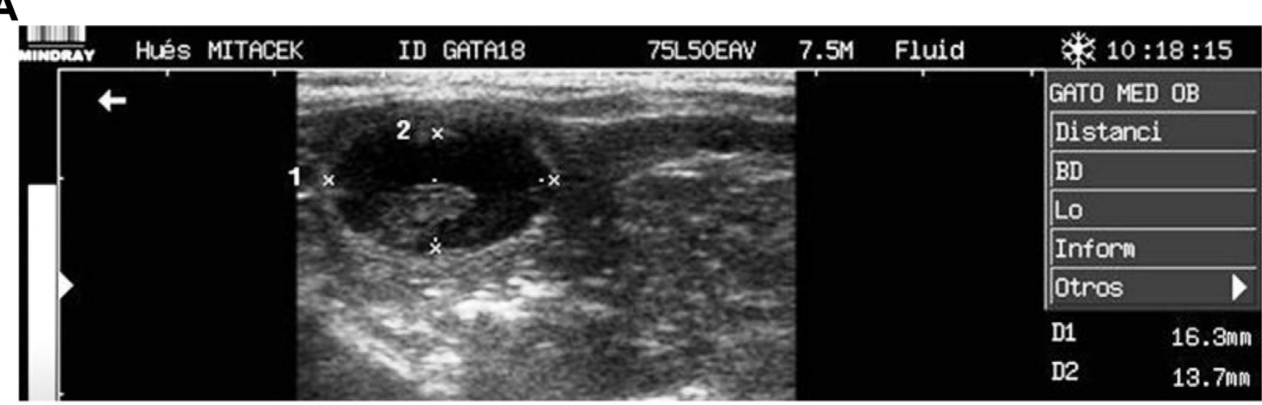

B

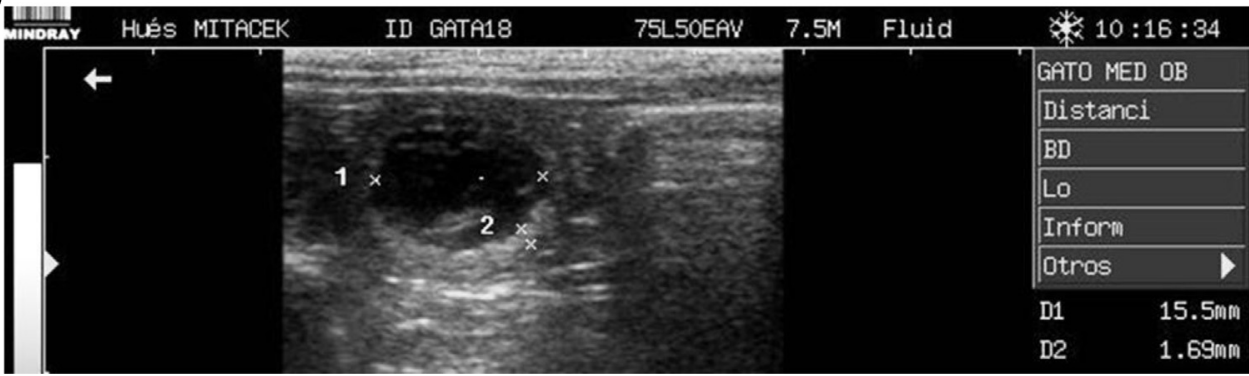

Fig. 1. (A). Day 21 of pregnancy, ultrasound section of gestational sac (GS). Longitudinal dimensions of GS: caliper one, length (LEN, mm); caliper two, anteriorposterior (ATP, mm). Ultrasound scanner with a 7.5-MHz linear transducer. (B). Day 21 of pregnancy, ultrasound section of gestational sac (GS). Transverse dimensions of GS: caliper one, width (WID, mm); caliper two, uterine wall thickness (UW, mm). Ultrasound scanner with a 7.5-MHz linear transducer.

After treatment, queens were daily monitored by ultrasonography for 10 days and weekly until the end of gestation to obtain gestational sacs (GS) and fetal measurements. Food and water were not restricted prior to the ultrasound examination. Transabdominal ultrasonographic examinations were performed with the queens positioned in dorsal recumbency. The queens were not sedated or anesthetized. Before the first ultrasonographic examination and every 5 days, the hair on the ventral abdomen was clipped. Acoustic coupling gel was applied to the skin of the ventral abdomen. The abdomen was scanned just cranial to the pubis, where the bladder and colon were identified as landmarks for the uterus. Once located; the uterine body, bifurcation, and horns were scanned in a transverse and sagittal plane. Dimensional measurements of GS were made and recorded from gestational Day 21 to 22 to 10 days' after treatment (EXP I) and GS, fetal measurements, and fetal biophysical profile score were made and recorded from gestational Day 35 to 38 to 10 days' after treatment (EXP II). All measurements were made with electronic calipers from appropriate frozen images. At each examination, two sets of images of GS and fetal measurements were recorded for each queen, regardless of number of fetuses present.

During each ultrasound examination, GS were measured from longitudinal and transverse images. From longitudinal images, the length (LEN, $\mathrm{mm}$ ) and anteriorposterior (ATP, mm) dimensions of GS were measured. From transverse images, the width (WID, mm) dimension of GS was measured. The GS volume (GSV, $\mathrm{mm}^{3}$ ) was calculated by the prolate ellipse formula $\left(4 / 3 \pi^{*}[\mathrm{GSLEN} / 2]^{*}\right.$ [GSATP/2] $\left.]^{*}[\mathrm{GSWID} / 2]\right)$ and GS diameter (GSD, mm) was calculated averaging three orthogonal measurements made from frozen images. In addition, the uterine wall thickness (UW; Fig. 1A, B) was measured $[13,16]$. During the treatment, ultrasound changes in cavity reduction and particles fill up in the GS were evaluated (Tables 1 and 2).

Fetal measurements included crown-rump length (CRL), head diameter (HD), and body diameter (BD). The CRL length was measured along the longest axis of the fetus $[13,21]$. Transverse HD was measured from a dorsal plane image. Image quality of HD was initially assessed by a symmetric frontal scanning of the skull with an evident falx cerebri; and the BD was measured from a transverse image of the abdomen at the level of the stomach, as previously described by Beck et al [13,22] (Fig. 2A-C).

Fetal biophysical profile is a score ad hoc derived from observation of three discrete dynamic fetal biophysical variables (fetal heart rate [FHR] in heartbeats per minute, gross body movement [GBM], and GSV). The score can range from $6 / 6$ (all variables normal) to $0 / 6$ (all variables abnormal; Table 3) [16,17,21]. The normal number of GBM was calculated in PLA group. Daily, the fetuses were observed by ultrasonography and fetal movements were recorded during a minute. Ultrasonographic examinations were performed by MCGM.

When the treatment finished, returned to the estrus after pregnancy interruption or parturition we registered. In the second estrus, each queen was placed with the tom for 48 hours. The first mating was documented, and pregnancies were confirmed by abdominal palpation and transabdominal ultrasonographic examination 20 days after the first mating. 
Table 1

The ultrasound scoring system of particles in the gestational sacs (PGS).

\begin{tabular}{|c|c|c|}
\hline Score & Description & Ultrasound image \\
\hline 0 & Normal GS & \\
\hline 1 & The particles fill up to $25 \%$ of the GS & \\
\hline 2 & The particles fill up to $50 \%$ of the GS & \\
\hline 3 & The particles fill up to $75 \%$ of the GS & \\
\hline
\end{tabular}

Abbreviation: GS, gestational sac.

\subsection{Statistical analyses}

Data are shown as least squares means \pm standard errors. Statistical significance was set at $\mathrm{P}<0.05$. The queen was considered the experimental units.

Ultrasonographic measurement of the GS (LEN, ATP, WID, GSV, GSD, UW, particles in the gestational sacs [PGS], and reduction of the gestational sacs [RGS]), fetal measurements (CRL, HD, and BD), FBP (FHR, GBM, and GSV), and serum $\mathrm{P}_{4}$ concentrations were analyzed by PROC MIXED from SAS 9.1 as repeated measures [23]. The model included the random effect of the queen and the fixed effects of time (days of treatment, treatment [ALI vs. CLO vs. PLA], and interaction of treatment by day of treatment). A polynomial contrast was used to test the linear, quadratic, and cubic effects [18]. The area under the curve (AUC) was analyzed by Sigma plot 10.0 [24].

Days of gestation (DG), days from treatment to the presence of vulvar discharge (DTDV), days from pregnancy interruption to the return to estrus were analyzed by the PROC GLM of SAS 9.1 [23]. The logistic model included the fixed effect of treatment and days of treatment. The number of kittens was analyzed with PROC GENMOD of SAS 9.1 with Poisson regression and log link functions [23]. The logistic model included the fixed effect of treatment and days of treatment. Statistical analysis was performed by MCGM and RLS.

\section{Results}

\subsection{EXP I}

While all queens treated with ALI terminated pregnancy (10/10, 100\%), none of those treated with CLO- $(0 / 10,0 \%)$ or with PLA (0/10, 0\%) terminated pregnancy $(\mathrm{P}<0.0001)$. The interval from treatment to first signs of pregnancy termination in the ALI group was significantly shorter than the interval from treatment to the end of a normal pregnancy in the CLO- and PLA-treated queens (4.30 \pm 0.60 vs. $43.2 \pm 0.60$ vs. $43.0 \pm 0.60$ days, $\mathrm{P}<0.001)$. One queen of the ALI group had three GS on Day 21, two of them began a pregnancy interruption at 4 days after beginning the treatment. However, one fetus remained intrauterine which was aborted 42 days after beginning the treatment. The average DG for queens with normal pregnancy were similar in CLO and PLA groups (64.6 \pm 0.61 vs. $64.2 \pm 0.61$ days, $\mathrm{P}>0.65)$. The number of $\mathrm{GS}$ at the beginning of the study was similar in ALI, CLO, and PLA 
Table 2

The ultrasound scoring system of reduction of the gestational sacs (RGS).

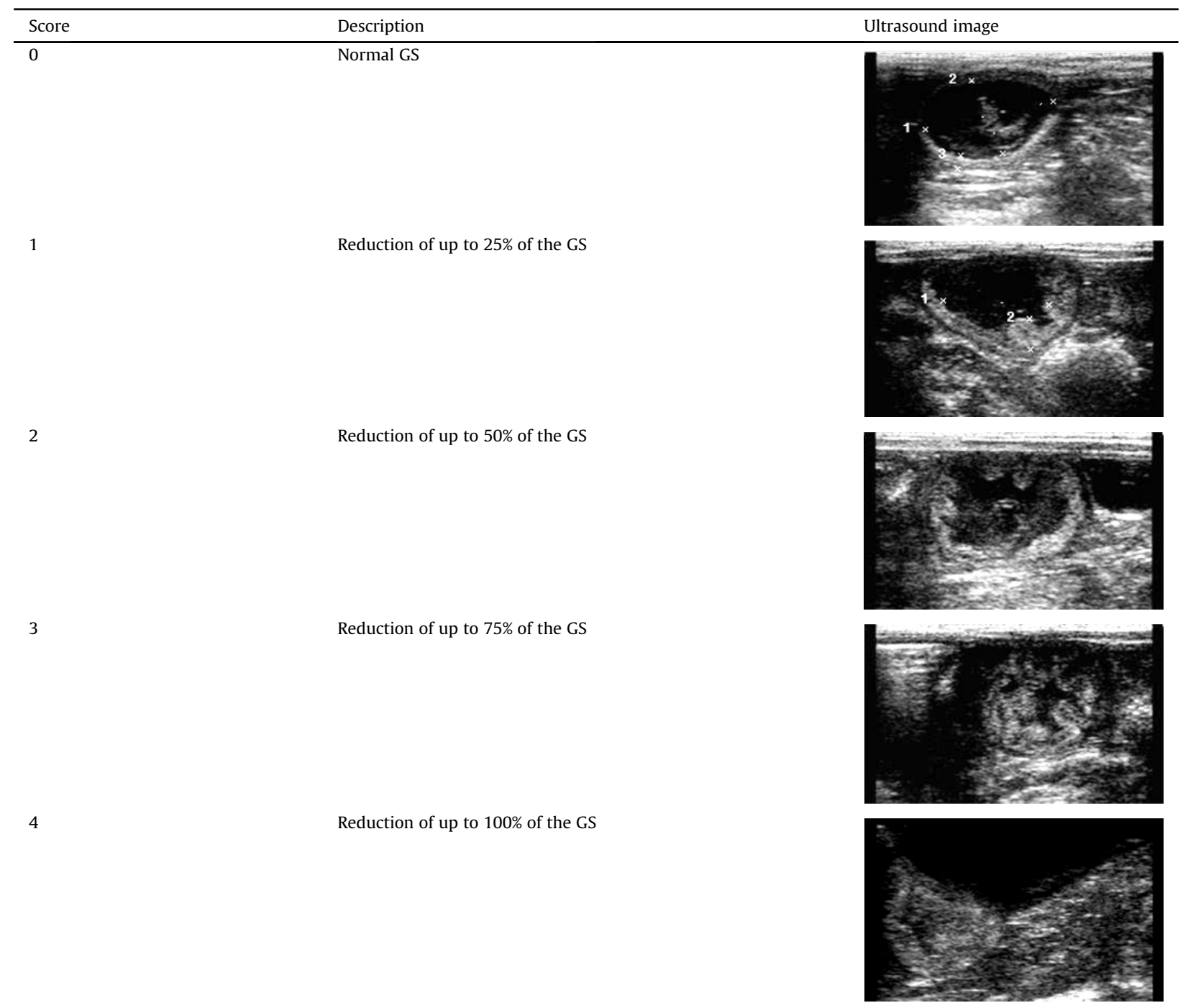

Abbreviation: GS, gestational sac.

groups $(2.70 \pm 0.33,3.30 \pm 0.33$ and $3.00 \pm 0.33, \mathrm{P}>0.45$; respectively). The number of kittens born from normal pregnancies was similar in the CLO- and PLA-treated group ( $3.7 \pm 0.29$ vs. $3.2 \pm 0.29, \mathrm{P}>0.24)$, and $100 \%$ of the animals were weaned. The interval from the beginning of treatment to presence of vulvar discharge in the ALI group was $7.42 \pm 0.92$ days.

Serum $\mathrm{P}_{4}$ concentration was not significantly different between ALI, CLO, and PLA group at beginning of the treatment $(22.92 \pm 2.41,23.4 \pm 2.41$, and $29.4 \pm 2.54 \mathrm{ng} / \mathrm{mL}$, respectively). On Day 6 in ALI and CLO groups, serum $\mathrm{P}_{4}$ concentration was significantly different than in PLA group. The main effect of treatment, and the interaction of treatment by day and treatment by serum $\mathrm{P}_{4}$ concentrations were significant $(40.90 \pm 2.65,19.40 \pm 2.17$, and $29.25 \pm 2.30 \mathrm{ng} / \mathrm{mL}, \mathrm{P}<0.0001$; respectively). Twenty-four hours after the treatment, serum $\mathrm{P}_{4}$ concentrations were significantly lower in CLO group compared with ALI and PLA $(14.47 \pm 2.17,28.39 \pm 2.17$, and $29.36 \pm 2.17 ; \mathrm{P}<0.005$ respectively). On Day 9 after the treatment, no significant difference in serum P4 concentrations were observed between ALI, CLO, and PLA groups (Fig. 3). The AUC serum $\mathrm{P}_{4}$ concentration were smaller in CLO group than in ALI and PLA group from Day 0 to Day 5 after treatment $(61.96 \pm 13.72 \mathrm{ng} \mathrm{d} / \mathrm{mL}$ vs. $156.99 \pm 14.47 \mathrm{ng} \mathrm{d} / \mathrm{mL}$, $\mathrm{P}<0.001)$. However, during the same period, the AUC of serum $\mathrm{P}_{4}$ concentration was similar between ALI and PLA group (166.06 $\pm 14.47 \mathrm{ng} \mathrm{d} / \mathrm{mL}$ vs. $147.92 \pm 14.47 \mathrm{ng} \mathrm{d} / \mathrm{mL}$, $\mathrm{P}>0.38$ ). The AUC serum $\mathrm{P}_{4}$ concentrations were smaller in CLO group than in ALI. Furthermore, from Day 5 to Day 8 after the treatment, the AUC serum $\mathrm{P}_{4}$ concentrations were smaller in CLO group than in ALI and PLA group 


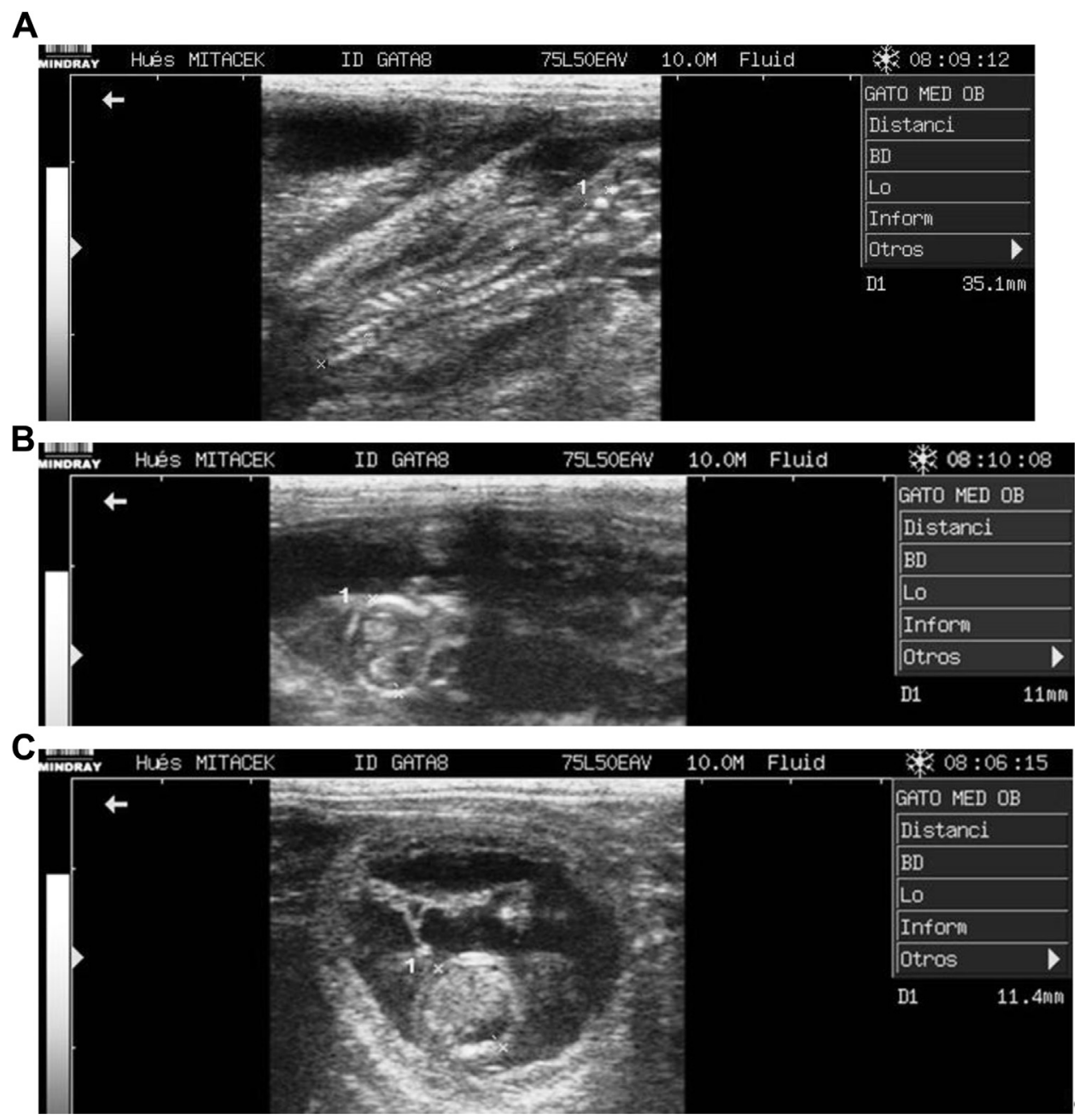

Fig. 2. (A). Day 36 of pregnancy. Crown-rump length: caliper one (CRL, mm). Ultrasound scanner with a 10-MHz linear transducer. (B). Day 36 of pregnancy. Head diameter: caliper one (HD, mm). Ultrasound scanner with a 10-MHz linear transducer. (C). Day 36 of pregnancy. Body diameter: caliper one (BD, mm). Ultrasound scanner with a $10-\mathrm{MHz}$ linear transducer.

$(60.36 \pm 8.93 \mathrm{ng} \mathrm{d} / \mathrm{mL}$ vs. $121.28 \pm 13.14 \mathrm{ng} \mathrm{d} / \mathrm{mL}$ $\mathrm{P}<0.001)$. However, during the same period, the AUC serum $\mathrm{P}_{4}$ concentrations were smaller in CLO group than in ALI. The AUC serum $\mathrm{P}_{4}$ concentrations were smaller in CLO group than in ALI. The AUC serum $\mathrm{P}_{4}$ concentration were greater in ALI group than PLA group $(156.16 \pm 16.31 \mathrm{ng} \mathrm{d} / \mathrm{mL}$ vs. $86.41 \pm 9.98 \mathrm{ng} \mathrm{d} / \mathrm{mL}, \mathrm{P}<0.001$ ).

At the start of the study, all GS measurements were similar for all treatment groups (LEN [P $>0.85$ ], ATP $[P>0.54]$, WID [P $>0.17]$, GSV $[P>0.24]$, and GSD

Table 3

Biophysical profile scoring: technique and interpretation.

\begin{tabular}{lll}
\hline $\begin{array}{l}\text { Biophysical } \\
\text { variable }\end{array}$ & Normal (score 2) & Abnormal (score 0) \\
\hline FHR & $\geq 220 \mathrm{bpm}$ & $<220 \mathrm{bpm}$ \\
GBM & $\geq 7$ movements in $1 \mathrm{~min}$ & $<7$ movements in $1 \mathrm{~min}$ \\
GSV & Increase & Decrease or maintain \\
\hline
\end{tabular}

Abbreviations: bpm, heartbeat per minute; FHR, fetal heart rate; GBM, gross body movement; GSV, gestational sac volume.

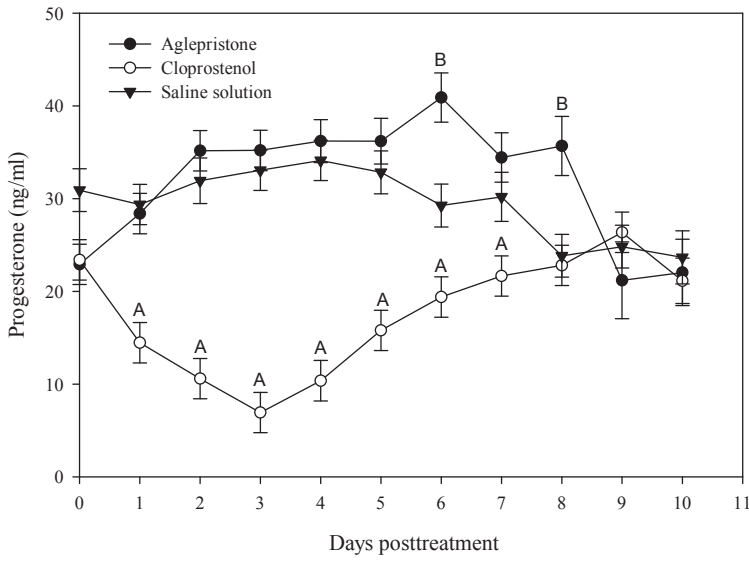

Fig. 3. Least squares means \pm standard errors of $\mathrm{P}_{4}(\mathrm{ng} / \mathrm{mL})$ during PLA, ALI (10 $\mathrm{mg} / \mathrm{kg}$, on 2 consecutive days), or CLO $(5 \mu \mathrm{g} / \mathrm{kg}$, on 3 consecutive days) treatment at 21 to 22 days of gestation. Superscripts differ at $\mathrm{P}<0.05$. ALI, aglepristone; CLO, cloprostenol. 

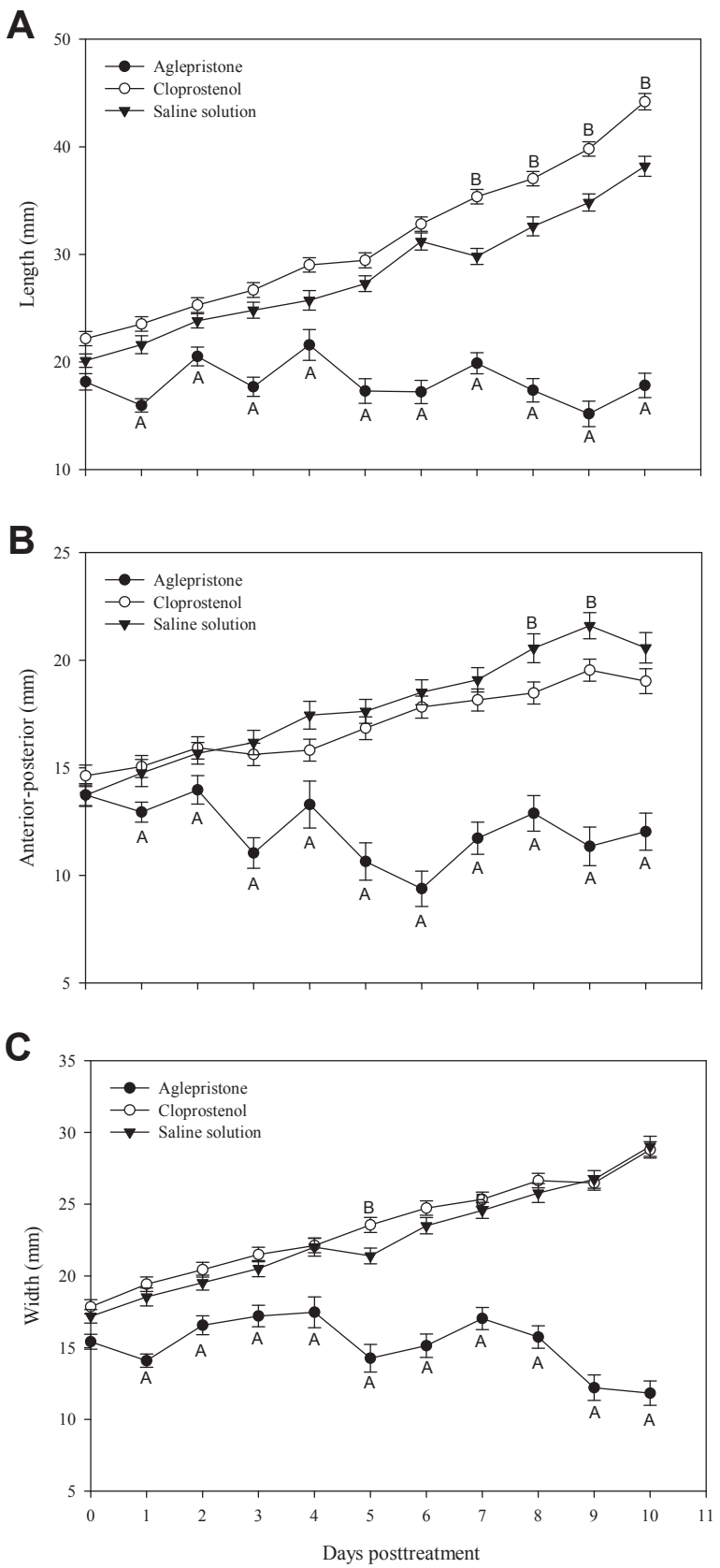

Fig. 4. Least squares means \pm standard errors of dimensions LEN (mm, A), ATP (mm, B), WID (mm, C) of SG during PLA, ALI (10 mg/kg, on 2 consecutive days), or CLO (5 $\mu \mathrm{g} / \mathrm{kg}$, on 3 consecutive days) treatment at 21 to 22 days of gestation. Superscripts differ at $\mathrm{P}<0.05$. ALI, aglepristone; ATP, anteriorposterior; CLO, cloprostenol; LEN, length; WID, width.

[P > 0.07]). The GS measurements (LEN, ATP, WID, GSV, and GSD) increased at different rate among treatments across DG (interaction of treatment by day of gestation; $\mathrm{P}<0.0001$, Figs. 4 and 5). In the group of queens that pregnancy was terminated (ALI), all GS measurements did not increase after treatment. To the contrary, in the groups with normal pregnancy (CLO and PLA), GS measurements continued to increase during the next 10 days after
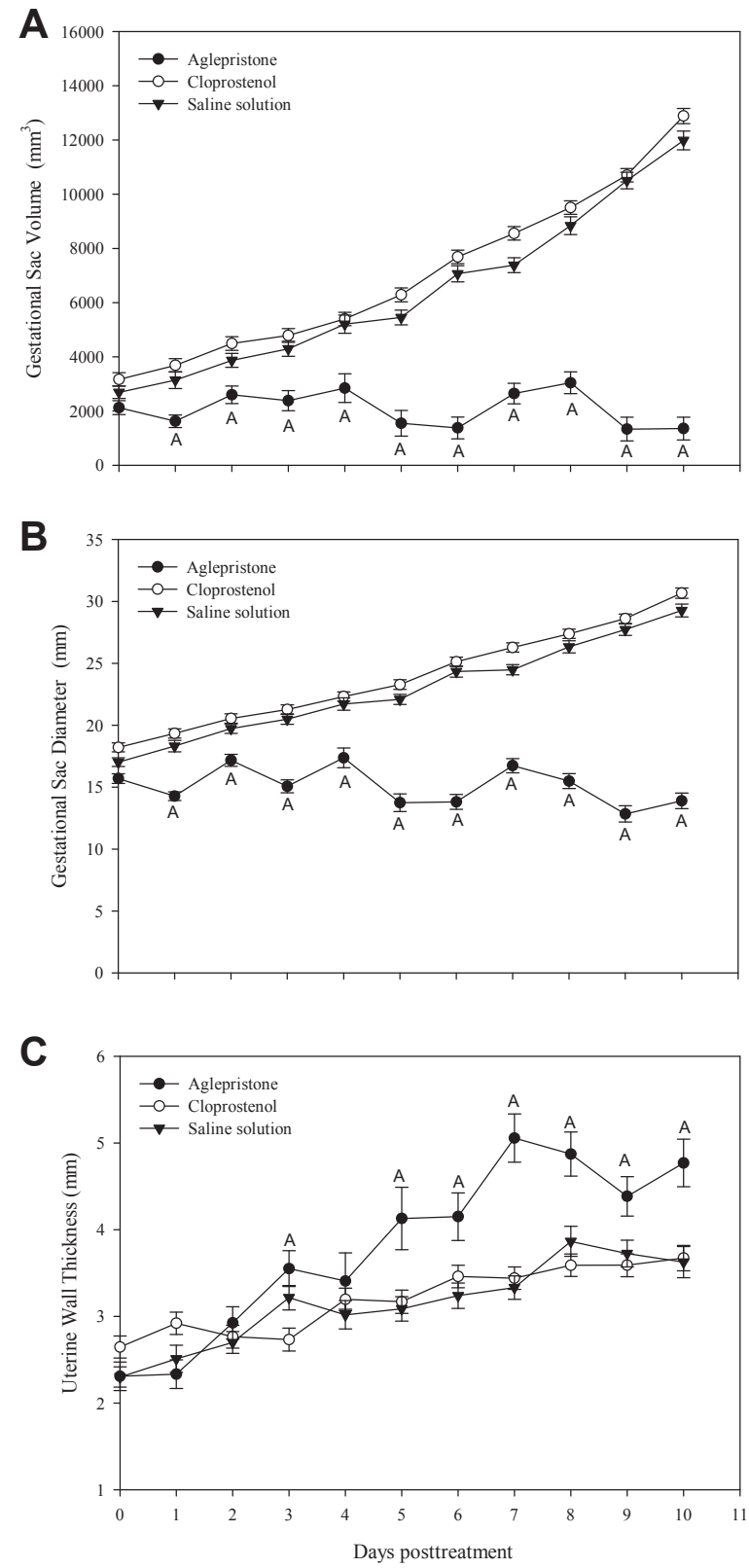

Fig. 5. Least squares means \pm standard errors of dimensions GSV $\left(\mathrm{mm}^{3}, \mathrm{~A}\right)$, GSD (mm, B), UW (mm, C) of GS during PLA, ALI (10 mg/kg, on 2 consecutive days), or CLO (5 $\mu \mathrm{g} / \mathrm{kg}$, on 3 consecutive days) treatment at 21 to 22 days of gestation. Superscripts differ at $\mathrm{P}<0.05$. CLO, cloprostenol; GS, gestational sac; GSD, gestational sac diameter; GSV, gestational sac volume; UW, uterine wall.

treatment $(\mathrm{P}<0.01$, Figs. 4 and 5). At the start of the study, UW was similar for all treatment groups $(P>0.31)$. However, the UW was greater in ALI vs. CLO or PLA group at Day 3 and Days 5 to 11 (Fig. 5). In addition, at the beginning of the treatment, PGS and RGS were similar for all treatment groups. Particles in the gestational sacs increased after the treatment in the ALI group and were higher than CLO and PLA groups at all time points $(\mathrm{P}<0.0001)$. Reduction of the gestational sacs also increased after the treatment in the 

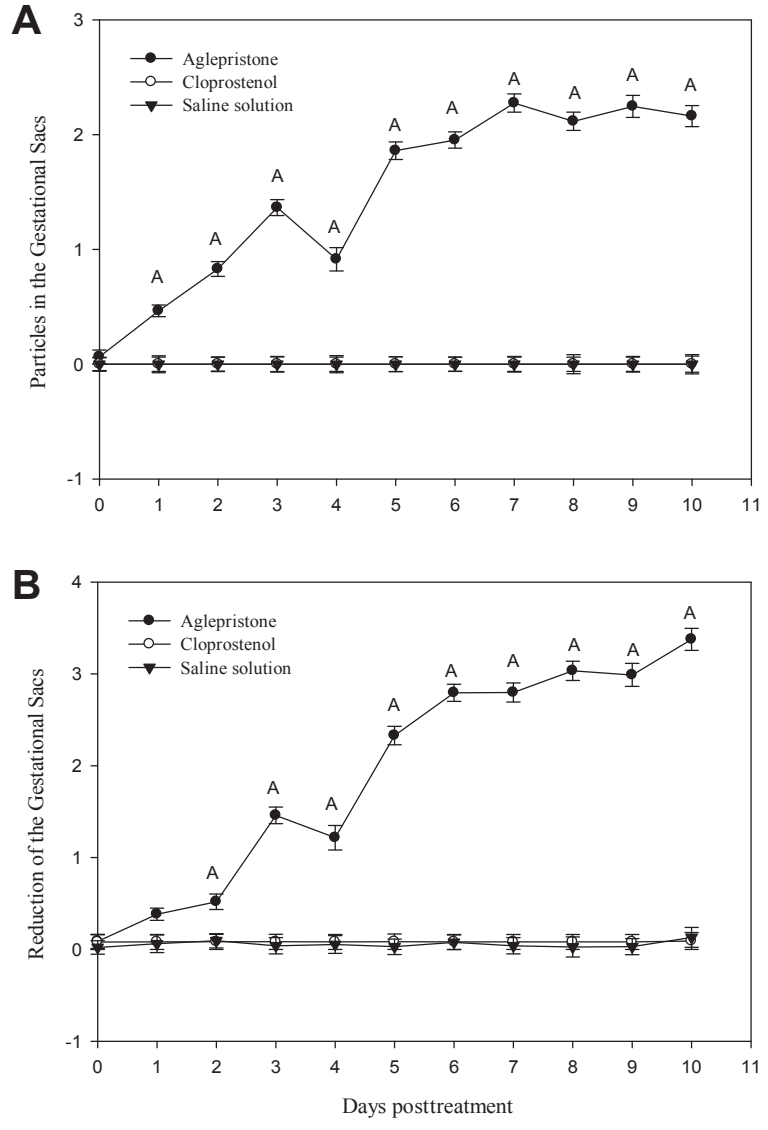

Fig. 6. Least squares means \pm standard errors of dimensions PGS (A), RGS (B) of GS during PLA, ALI (10 mg/kg, on 2 consecutive days), or CLO (5 $\mu \mathrm{g} / \mathrm{kg}$, on 3 consecutive days) treatment at 21 to 22 days of gestation. Superscripts differ at $\mathrm{P}<0.05$. ALI, aglepristone; CLO, cloprostenol; GS, gestational sac.

ALI group and was higher than the CLO and PLA groups at Day 2 after the treatment $(P<0.0001$; Fig. 6$)$.

The return to estrus after pregnancy termination or after normal pregnancy was similar in ALI, CLO, and PLA groups (62.8 \pm 8.69, $49.0 \pm 8.69,57.8 \pm 8.69$ days, $\mathrm{P}>0.53$; respectively). Treatment did not affect the subsequent fertility in both ALI and CLO groups, since the queens became pregnant (pregnancy rate 100\%) in the first mating after the treatment. The average DG were similar in the ALI and CLO group ( $64.8 \pm 0.62$ vs. $65.0 \pm 0.62$ days, $\mathrm{P}>0.82)$. The number of kittens born from normal pregnancies was similar in the ALI and CLO group ( $2.8 \pm 0.31$ vs. $3.3 \pm 0.31$, $\mathrm{P}>0.27$ ) and $100 \%$ of the animals were weaned.

After CLO administration, all animals vomited and were depressed for 30 minutes. No side effects were seen with ALI-treated animals.

\subsection{EXP II}

While all queens treated with ALI terminated pregnancy (10/10,100\%), only one treated with CLO (1/10,10\%) aborted 5 days after the beginning of the treatment, and none of PLA $(0 / 10,0 \%)$ reported abortion $(P<0.0001)$. The interval from treatment to pregnancy termination was similar

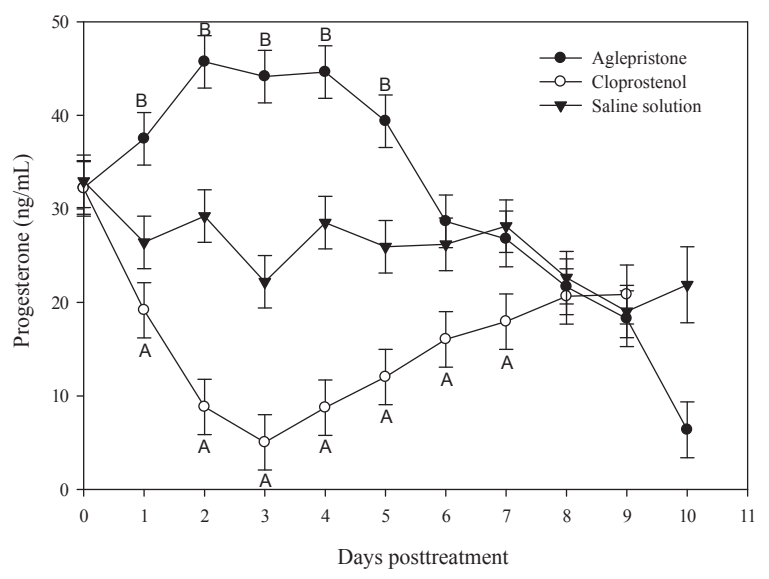

Fig. 7. Least squares means \pm standard errors of $\mathrm{P}_{4}(\mathrm{ng} / \mathrm{mL})$ during PLA, ALI (10 $\mathrm{mg} / \mathrm{kg}$, on 2 consecutive days) or CLO ( $5 \mu \mathrm{g} / \mathrm{kg}$, on 3 consecutive days) treatment at 35 to 38 days of gestation. Superscripts differ at $\mathrm{P}<0.05$. ALI, aglepristone; CLO, cloprostenol; $\mathrm{P}_{4}$, progesterone.

between ALI- and CLO-treated queens ( $4.1 \pm 0.31$ vs. five days, $\mathrm{P}>0.41$ ). The interval from the beginning of treatment to presence of vulvar discharge in aborted queen was similar between ALI and CLO groups ( $4.0 \pm 0.29$ vs. 3 days, $P>0.33)$. The average DG for queens with normal pregnancy were similar in CLO and PLA groups ( $65.0 \pm 0.46$ vs. $65.2 \pm 0.44$ days, $\mathrm{P}>0.76$ ). The number of kittens born from normal pregnancies was similar in the CLO and PLA group ( $3.44 \pm 0.41$ vs. $3.5 \pm 0.39, P>0.93)$ and $100 \%$ of the kittens were weaned.

Serum $\mathrm{P}_{4}$ concentration was not different between ALI, CLO, and PLA group at the beginning of the treatment (32.25 $\pm 2.8,32.2 \pm 2.96$, and $32.96 \pm 2.8 \mathrm{ng} / \mathrm{mL}, \mathrm{P}>0.99)$. On Day 1 in ALI and CLO groups, serum $\mathrm{P}_{4}$ concentrations were significantly different than in PLA group. The main effect of treatment, and the interaction of treatment by day, and treatment by serum $\mathrm{P}_{4}$ concentrations were significant $(37.80 \pm 2.80,19.16 \pm 2.96$, and $26.43 \pm 2.80 \mathrm{ng} / \mathrm{mL}$, $\mathrm{P}<0.0001$; respectively). Twenty-four hours after the treatment, serum $\mathrm{P}_{4}$ concentrations were significantly lower in CLO group compared with ALI and PLA (19.16 \pm 2.96 , $37.5 \pm 2.80$, and $26.43 \pm 2.80 ; \mathrm{P}<0.01$ respectively). On Day 8 after the treatment, no significant difference in serum P4 concentrations were observed between ALI, CLO, and PLA groups (Fig. 7). From Day 0 to Day 5 after the treatment, the AUC of serum $\mathrm{P}_{4}$ concentration was smaller in CLO group than in ALI and PLA group (67.55 $\pm 19.5 \mathrm{ng} \mathrm{d} / \mathrm{mL}$ vs. $171.86 \pm 18.53 \mathrm{ng} \mathrm{d} / \mathrm{mL}, \mathrm{P}<0.001)$. However, during the same period, the AUC of serum $\mathrm{P}_{4}$ concentration was greater in ALI group than PLA group (207.85 $\pm 18.53 \mathrm{ng} \mathrm{d} / \mathrm{mL}$ vs. $135.88 \pm 18.53 \mathrm{ng} \mathrm{d} / \mathrm{mL}, \mathrm{P}<0.01)$. From Day 5 to Day seven after the treatment, the AUC of serum $\mathrm{P}_{4}$ concentration was smaller in CLO group than in ALI and PLA group (31.02 $\pm 7.34 \mathrm{ng} \mathrm{d} / \mathrm{mL}$ vs. $55.95 \pm 7.15 \mathrm{ng} \mathrm{d} / \mathrm{mL}, \mathrm{P}<0.009)$. However, during the same period, the AUC of serum $\mathrm{P}_{4}$ concentration was greater in ALI group than PLA group $(58.63 \pm 7.34 \mathrm{ng} \mathrm{d} / \mathrm{mL}$ vs. $53.28 \pm 6.96 \mathrm{ng} \mathrm{d} / \mathrm{mL}, \mathrm{P}<0.60)$.

One day after treatment initiation, there were no significant differences in GS (LEN [P $>0.22$ ], ATP [P $>0.88$ ], 


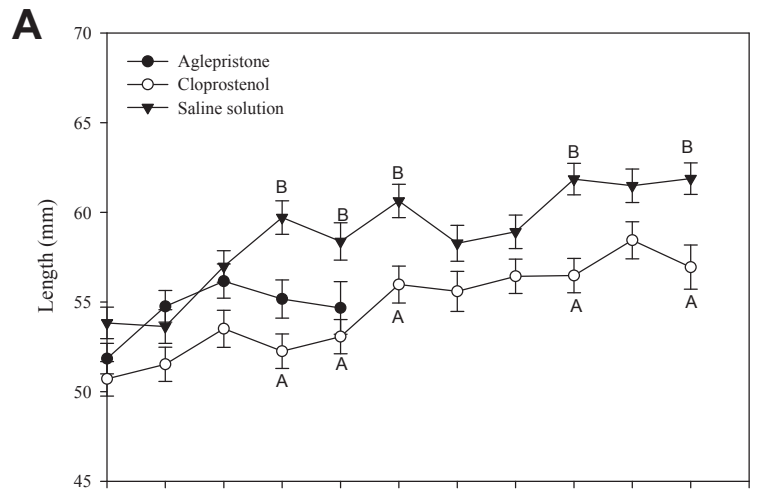

B
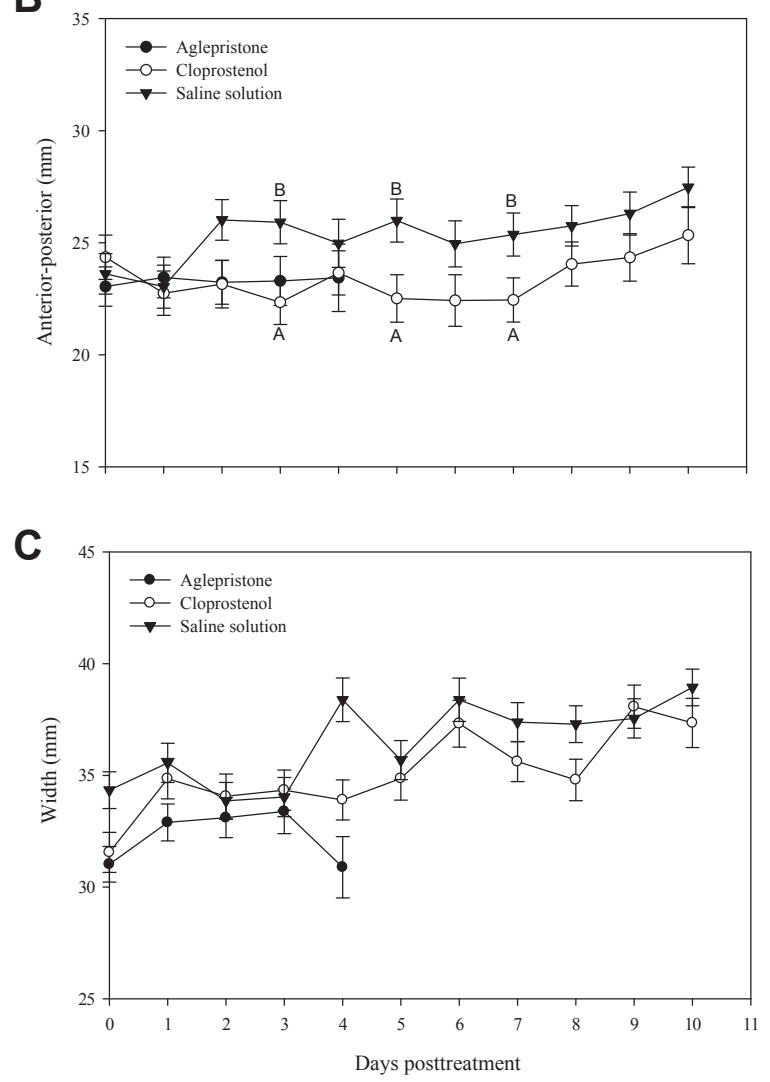

Fig. 8. Least squares means \pm standard errors of dimensions LEN (mm, A), ATP (mm, B), WID (mm, C) of SG during PLA, ALI (10 mg/kg, on 2 consecutive days), or CLO (5 $\mu \mathrm{g} / \mathrm{kg}$, on 3 consecutive days) treatment at 35 to 38 days of gestation. Superscripts differ at $\mathrm{P}<0.05$. ALI, aglepristone; ATP, anteriorposterior; CLO, cloprostenol; LEN, length; WID, width.

WID [P $>0.11]$, GSV [P $>0.28]$, and GSD [P $>0.24])$ and fetal measurements (CRL $[\mathrm{P}>0.70]$, HD $[\mathrm{P}>0.06]$ and $\mathrm{BD}$ $[P>0.44])$ among treatments $(P>0.05)$. The GS and fetal measurements (LEN, ATP, WID, GSV, GSD, CRL, HD, and BD) increased at different rates among treatments across DG (interaction of treatment by day of gestation; $\mathrm{P}<0.0001$, Figs. 8-10). In addition, PLA-treated animals had a greater increase of GS and fetal measurements compared ALI- and CLO-treated animals $(\mathrm{P}>0.05)$. Although in ALI and CLO
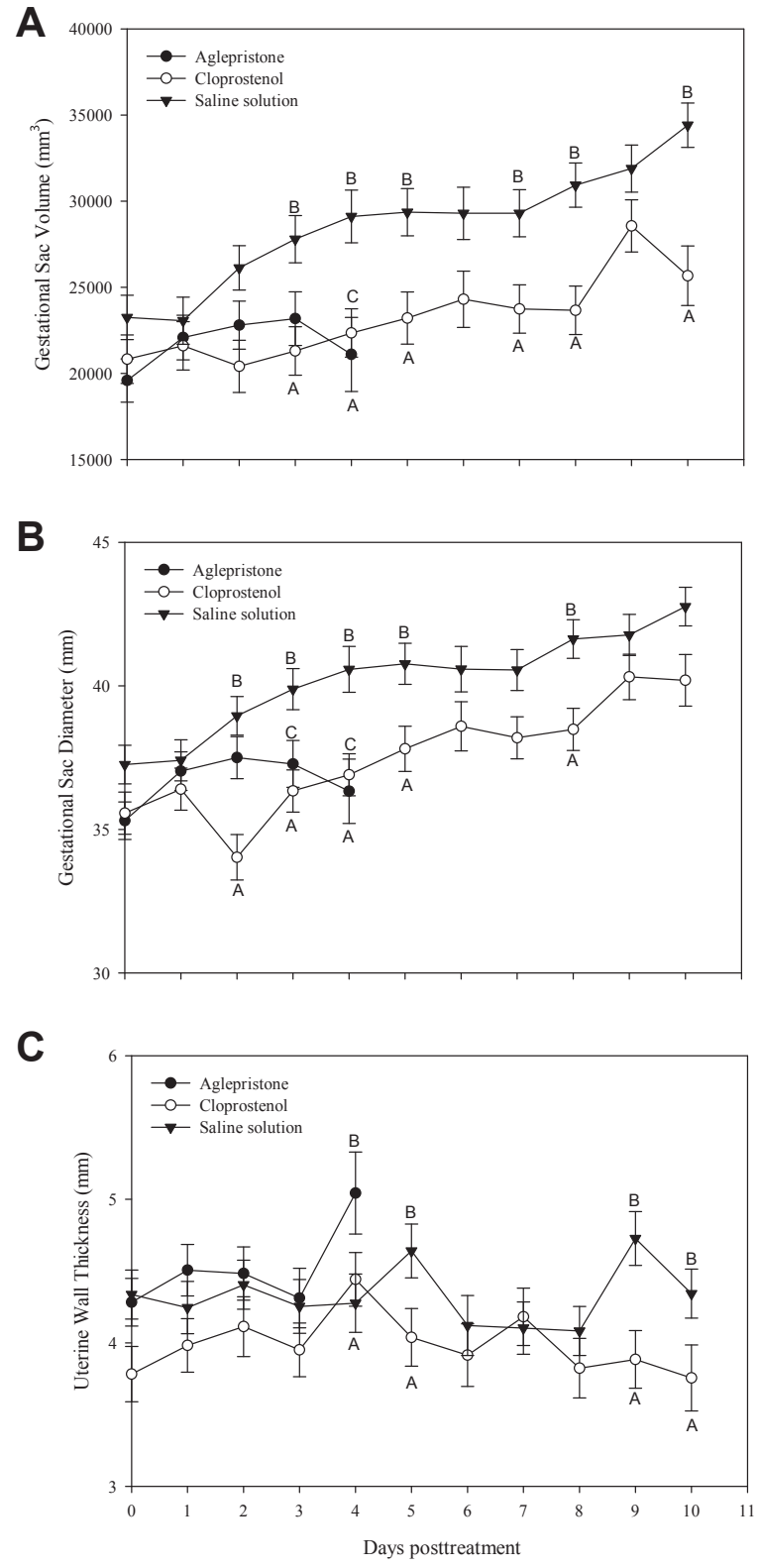

Fig. 9. Least squares means \pm standard errors of dimensions GSV $\left(\mathrm{mm}^{3}, \mathrm{~A}\right)$, GSD (mm, B), UW (mm, C) of GS during PLA, ALI (10 mg/kg, on 2 consecutive days), or CLO (5 $\mu \mathrm{g} / \mathrm{kg}$, on 3 consecutive days) treatment at 35 to 38 days of gestation. Superscripts differ at $\mathrm{P}<0.05$. CLO, cloprostenol; GS, gestational sac; GSD, gestational sac diameter; GSV, gestational sac volume; UW, uterine wall.

groups, GS and fetal measurements increased after treatment $(P>0.05)$, there were no significant differences between GS and fetal measurements between ALI group and the queen that aborted in CLO group $(P>0.05)$. At the start of the study, UW was similar for all treatment groups $(P>0.12)$. In the ALI group, UW was significantly higher at Day 4 after the treatment than PLA group (Fig. 9).

The average of the GBM recorded in PLA group was $\geq 7$ movements in 1 minute. No significant differences were observed in the FHR and GBM between ALI, CLO, and PLA 

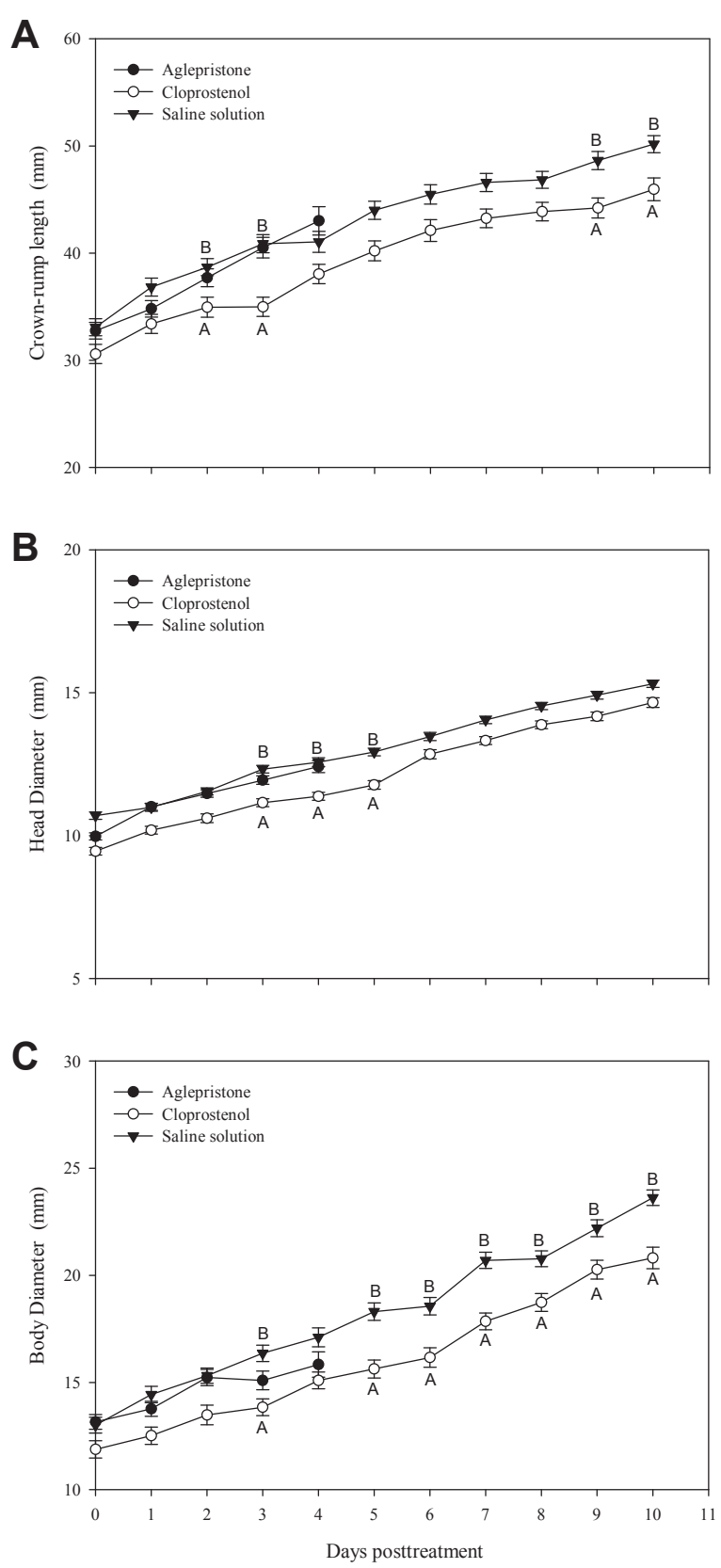

Fig. 10. Least squares means \pm standard errors of dimensions CRL (mm, A), $\mathrm{HD}(\mathrm{mm}, \mathrm{B})$, and BD $(\mathrm{mm}, \mathrm{C})$ during PLA, ALI $(10 \mathrm{mg} / \mathrm{kg}$, on 2 consecutive days), or CLO (5 $\mu \mathrm{g} / \mathrm{kg}$, on 3 consecutive days) treatment at 35 to 38 days of gestation. Superscripts differ at $\mathrm{P}<0.05$. ALI, aglepristone; BD, body diameter; CLO, cloprostenol; CRL, crown-rump length; HD, head diameter.

groups during the treatment ([FHR $1.8 \pm 0.16,2.0 \pm 0.17$, $1.77 \pm 0.17, \mathrm{P}>0.62]$, [GBM $1.0 \pm 0.33,1.1 \pm 0.35,1.1 \pm 0.35$, $\mathrm{P}>0.96]$; respectively). Similar results were obtained in the GSV between CLO and PLA groups (1.5 \pm 0.29 vs. $1.7 \pm 0.29 \mathrm{P}>0.59$; respectively). On the contrary, significant differences were observed in the GSV between ALI and PLA groups $(0.8 \pm 0.27$ vs. $1.77 \pm 0.29$, $\mathrm{P}>0.02$; respectively). However, no significant differences were obtained in the FBP between ALI, CLO, and PLA groups (3.6 \pm 0.46 , $4.6 \pm 0.49,4.6 \pm 0.49, \mathrm{P}>0.20$; respectively).

The return to estrus after pregnancy termination or parturition was similar in ALI, CLO, and PLA groups $(34.4 \pm 5.84,40.42 \pm 6.98,43.3 \pm 5.84$ days, $\mathrm{P}>0.55$; respectively). Treatment did not interfere with subsequent fertility in both ALI and CLO groups, since the queens became pregnant (pregnancy rate 100\%) in the first mating after the treatment. The average DG were similar in the ALI and CLO group (65.0 \pm 0.67 vs. $64.2 \pm 0.75$ days, $\mathrm{P}>0.47$ ). The number of kittens born from normal pregnancies was similar in the ALI and CLO group ( $2.6 \pm 0.22$ vs. $2.5 \pm 0.25$, $\mathrm{P}>0.77$ ) and $100 \%$ of kittens were weaned.

After CLO administration, all animals vomited and were depressed for 30 minutes. No side effects were seen with ALI treated animals.

\section{Discussion}

According to our hypothesis, we obtained changes in serum $\mathrm{P}_{4}$ concentration and ultrasonographic images during the treatment with ALI and CLO. The efficacy of CLO and ALI for pregnancy termination observed in the present work is in agreement with results previously obtained by García Mitacek et al. [11].

Fiéni et al. [9] reported that ALI administration produces a significant increase in $\mathrm{P}_{4}$ concentrations after 60 hours after administration. According with Fiéni study, we observed an increase in serum $\mathrm{P}_{4}$ concentrations after ALI administration and $\mathrm{P}_{4}$ remained high during 8 or 5 days after the treatment (21-22 days or 35-38 days treatment, respectively). This observation is also in agreement with previous reports in which the use of ALI acts as a true $\mathrm{P}_{4}$ antagonist on the uterus, thereby modifying serum $\mathrm{P}_{4}$ concentrations inducing pregnancy termination, without any immediate effects on luteal function $[9,25,26]$.

In contrast in CLO group, serum $\mathrm{P}_{4}$ concentration quickly declined 24 hours after initiation of treatment. However, in CLO group 4 days after treatment, $\mathrm{P}_{4}$ levels began to rise, and 8 days after treatment the serum $\mathrm{P}_{4}$ concentrations were similar to PLA group. The decline of serum $\mathrm{P}_{4}$ after prostaglandin administration observed in our work is in agreement with Shille and Stabenfeldt's [27] findings, who reported a decreased in serum $\mathrm{P}_{4}$ concentration and consequent depression of luteal function after PGF $2 \alpha$ administration in pseudopregnant queens. In the same way, other works have reported a decrease on serum $\mathrm{P}_{4}$ after natural or synthetic PG administration in queens [1,4,5]. In agreement with Braun et al. [2] and Siemieniuch et al. [28], in our work CLO group serum $\mathrm{P}_{4}$ concentrations increased 4 days after treatment and a complete development of pregnancy occurred. These findings which confirm the existence of a placental source of $\mathrm{P}_{4}$ were able to maintain pregnancy in queens. Likewise, recent findings on PGF metabolites in feces of domestic felids support a similar theory of different types of luteolysis in domestic cats. During the last 20 days of pregnancy, a significant increase in fecal PGF metabolites concentrations was observed, showing a luteolytic action of prostaglandin F2 $\alpha$. The first measurable increase in fecal PGF metabolites was found 4 weeks before parturition and coincides with the 
decrease in $\mathrm{P}_{4}$ concentration and appearance of cellular degradation in CL [29].

Although there are several studies on pregnancy interruption using different medical protocols, there has been no systematic description of the ultrasonic appearance of feline fetuses during pregnancy termination. Conversely, in this study, several ultrasonographic measurements were recorded to evaluate the embryo/fetal development and viability. Furthermore, data generated in this study could be useful to assess the risk of pregnancy loss in practice. In the same way, the measurement of serum $\mathrm{P}_{4}$ concentration could be useful to evaluate a normal luteal function and pregnancy development. The results obtained in our work, allowed detection of ultrasonographic and endocrinological changes after early- or mid-gestation interruption. Therefore, our results will be useful in feline reproduction practice. Early detection of fetal growth abnormalities allows to perform medical care. Thus, ultrasonographic and endocrinological studies throughout feline pregnancy are important for pregnancy monitoring and early medical intervention.

The FBP is used in pregnancy woman at high risk, allowing to estimated and reduce perinatal mortality and morbidity [17]. In contrast, in our work, we could not identify changes in relation with pregnancy interruption using FBP. The differences could be related with the number and frequency of observations. On the other hand, women have singleton pregnancies, whereas queens had multiple pregnancies. This fact makes difficult sequential ultrasonographic measurements in each fetus.

In our work, CLO-treated queens reported side effects reported in association with administration of PG [30]. A decline of PG side effects with repeated doses of the drug was reported in canines by Verstegen [31]. The same protocol could be used in queens to reduce the side effects associated with the administration of PG. In contrast, no side effects were found in the animals treated with ALI. However, in the study by Fiéni et al. [9], a small number of queens reported inflammation at the site of ALI injection, whereas four cats reported anorexia, depression, agitation, and diarrhea in the first 7 days of the treatment.

In our study, all treated queens returned to estrus after the treatment and became pregnant. Consistent with our results, Stabenfeldt and Shille [27] reported in queens treated with PG during pseudopregnancy a high pregnancy rate and normal parturition. Similar results reported by Fiéni et al. [9] who observed that all treated queens returned to estrus, $77 \%$ became pregnant in the postabortion heat and $10 \%$ in the second heat. Similarly, Onclin and Verstegen [4] have reported, queen fertility was not affected after a combined treatment with cabergoline and CLO. However, only $33 \%$ of the queens became pregnant after using a combined treatment with cabergoline and alfaprostol [1].

In conclusion, the results from this study indicate that data from ultrasonographic measurements made in the GS and fetuses are useful to detect changes of early- or midgestation interruption. In addition, the results show that administration of ALI or CLO during early- or mid-gestation did not impact fertility in the queen.

The changes observed in GS like presence and amount of particles and reduction of GS could be useful to detect early embryo-fetal distress and identify the risk of early- or midgestation pregnancy loss.

Therefore, the results obtained in our work could be applied in feline reproduction practice both to monitoring pregnancy health and medical gestation interruption for unwanted pregnancy.

\section{Acknowledgments}

This study was supported in part by UNLP grant V11/162 and V11/200 to RL de la Sota and MA Stornelli. In addition, MC García Mitacek was supported with a scholarship from CONICET.

\section{References}

[1] Erünal-Maral N, Aslan S, Findik M, Yüksel N, Handler J, Arbeiter K. Induction of abortion in queens by administration of cabergolina (Galastop) soley or in combination with the PGF2alfa analogue Alfaprostol (Gabbrostim). Theriogenology 2004;61: $1471-5$.

[2] Siemieniuch MJ, Jursza E, Szostek AZ, Skarzynski DJ, Boos A, Kowalewski MP. Steroidogenic capacity of the placenta as a supplemental source of progesterone during pregnancy in domestic cats. Reprod Biol Endocrinol 2012;10:89.

[3] Romagnoli S. Control of reproduction in dogs and cats: use and misuse of hormones. IVIS website with the permission of WSAVA. [Online]. p. 701-6, http://www.ivis.org/proceedings/wsava/2006/ lecture24/romagnoli4.pdf; 2006.

[4] Onclin K, Verstegen J. Termination of pregnancy in cats using a combination of cabergoline, a new dopamine agonist, and a synthetic PGF2 alpha, cloprostenol. J Reprod Fertil Suppl 1997;51: 259-63.

[5] Verstegen JP, Onclin K, Silva LD, Donnay I. Abortion induction in the cat using prostaglandin F2 alpha and a new anti-prolactinic agent, cabergoline. J Reprod Fertil Suppl 1993;47:411-7.

[6] Goericke-Pesch S, Georgiev P, Wehrend A. Prevention of pregnancy in cats using aglepristone on days 5 and 6 after mating. Theriogenology 2010;74:304-10.

[7] Georgiev P, Wehrend A. Mid-gestation pregnancy termination by the progesterone antagonist aglepristone in queens. Theriogenology 2006;65:1401-6.

[8] Georgiev P, Wehrend A. Histological changes of the feline cervix, endometrium and placenta after mid-gestacional termination of pregnancy with aglepristone. Reprod Domest Anim 2008;43: 409-14.

[9] Fiéni F, Martal J, Marnet PG, Siliart B, Guittot F. Clinical, biological and hormonal study of mid-pregnancy termination in cats with aglepristone. Theriogenology 2006;66:1721-8.

[10] Georgiev P, Bostedt H, Goericke-Pesch S, Dimitrov M, Petkov P, Stojanthev $\mathrm{K}$, et al. Induction of abortion with aglepristone in cats on day 45 and 46 after mating. Reprod Domest Anim 2010; 45:161-7.

[11] García Mitacek MC, Stornelli MC, Praderio R, Stornelli MA, de la Sota RL. Efficacy of use of cloprostenol or aglepristone at 21-22 and 35-38 days of gestation for pregnancy termination in queens. Reprod Domest Anim 2012;47:200-3.

[12] Senger PL. Placentation, the endocrinology of gestation and parturition. In: Senger PL, editor. Pathways to pregnancy and parturition. Second edition. Washington, USA: Current Conception, INC; 2003. p. 304-25.

[13] García Mitacek MC, Stornelli MC, Praderio RG, de la Sota RL, Stornelli MA. Ultrasonographic and progesterone changes during days 21 to 63 of pregnancy in queens. Theriogenology 2015;84: $1131-41$.

[14] Zschockelt L, Amelkina O, Siemieniuch MJ, Koster S, Jewgenow K, Braun BC. Corpora lutea of pregnant and pseudopregnant domestic cats reveal similar steroidogenic capacities during the luteal life span. J Steroid Biochem Mol Biol 2014;144:373-81.

[15] Zambelli D, Prati F. Ultrasonography for pregnancy diagnosis and evaluation in queens. Theriogenology 2006;66:135-44.

[16] Keats TE, Sistrom C. Atlas of radiological measurements. Seventh edition, Vol. 1. Mosby-doyma; 2002. p. 526-66.

[17] Manning FA, Morrison I, Harman CR, Lange IR, Menticoglou S. Fetal assessment based on fetal biophysical profile scoring: 
experience in 19,221 referred high-risk pregnancies. II. An analysis of false-negative fetal deaths. Am J Obstet Gynecol 1987;157: 880-4.

[18] Petersen RG. Design and Analysis of Experiments. New York: Marcel Dekker, Inc.; 1985. p. 429.

[19] Robledo MAM, Carneiro M, Raratella-Evêncio L, Evêncio-Neto ]. Avaliaçao do fotoperíodo na induçao do estro em gatas domésticas [Guest of photoperiod on estrus induction in domestic cats]. Rev Bras Reprod Anim 2003;27:274-5.

[20] Council for International Organizations of Medical Sciences (CflOoMS). International Guiding Principles for Biomedical Research Involving Animals. World Health Organization. https://grants.nih. gov/grants/olaw/Guiding_Principles_2012.pdf; 2012 [accessed 27. 10.16].

[21] Nyland TG, Mattoon JS. Ovaries and uterus. In: Nyland TG, Mattoon JS, editors. Small animal diagnostic ultrasound. Second edition. Philadelphia: W. B. Saunders Co; 2002. p. 231-49.

[22] Beck KA, Baldwin CJ, Bosu WTK. Ultrasound prediction of parturition in queens. Vet Radiol 1990;31:32-5.

[23] SAS ${ }^{\circ}$. SAS and STAT User's Guide, Release 9.1. Cary, NC: SAS Institute Inc.; 2003.

[24] Systat. Sigmaplot User's Guide, version 10.0. Chicago, IL: Systat Software, Inc.; 2006.

[25] Fiéni F, Bruyas JF, Battut I, Tainturier UD. Clinical use of antiprogestins in the bitch. In: Concannon PW, England G Verstegen J, Linde-Forsberg C, editors. Recent advances in small animal reproduction. Ithaca, NY: International Veterinary Information Service. http://www.ivis.org/home.asp; 2001 [accessed 27.10. 16].

[26] Galac S, Kooistra HS, Butinar J, Bevers MM, Dieleman SJ, Voorhout G, et al. Termination of mid-gestation pregnancy in bitches with aglépristone, a progesterone receptor antagonist. Theriogenology 2000;53:941-50.

[27] Shille VM, Stabenfeldt GH. Luteal function in domestic cat during pseudopregnancy after treatment with prostaglandin F2 $\alpha$. Biol Reprod 1979;21:1217-23.

[28] Braun BC, Zschockelt L, Dehnhard M, Jewgenow K. Progesterone and estradiol in cat placenta-Biosynthesis and tissue concentration. J Steroid Biochem Mol Biol 2012;132:295-302.

[29] Amelkina O, Braun BC, Dehnhard M, Jewgenow K. The corpus luteum of the domestic cat: histologic classification and intraluteal hormone profile. Theriogenology 2015;83:711-20.

[30] Wanke MM, Romagnoli S, Verstegen J, Concannon PW. Pharmacological approaches to pregnancy termination in dogs and cats including the use of prostaglandins, dopamine agonists, and dexamethasone [Online]. Ithaca, New York, USA: International Veterinary Information Service, http://www.ivis.org/home.asp; 2002 [accessed 27.10.16].

[31] Verstegen J, Dhaliwal G, Verstegen-Onclin K. Mucometra, cystic endometrial hyperplasia, and pyometra in the bitch: advances in treatment and assessment of future reproductive success. Theriogenology 2008;70:364-74. 